Review

\title{
Active Peptide-Conjugated Chitosan Matrices as an Artificial Basement Membrane
}

\author{
Kentaro Hozumi *, Jun Kumai, Yuji Yamada and Motoyoshi Nomizu \\ Department of Clinical Biochemistry, School of Pharmacy, Tokyo University of Pharmacy and \\ Life Sciences, 1432-1 Horinouchi, Hachioji, Tokyo 192-0392, Japan; \\ E-Mails: y071096@toyaku.ac.jp (J.K.); y041219@toyaku.ac.jp (Y.Y.); nomizu@toyaku.ac.jp (M.N.) \\ * Author to whom correspondence should be addressed; E-Mail: hozumi@toyaku.ac.jp; \\ Tel./Fax: +81-42-676-5670.
}

Academic Editor: Kell Mortensen

Received: 27 November 2014 / Accepted: 3 February 2015 / Published: 11 February 2015

\begin{abstract}
The basement membrane, a thin extracellular matrix, plays a critical role in tissue development and repair. Laminins are the major component of basement membrane and have diverse biological activities. We have identified various cell-adhesive peptides from laminins and their specific cell surface receptors. Polysaccharides, including chitosan, have been used as scaffolds, which regulate cellular functions for tissue engineering. We have developed laminin-derived active peptide-chitosan matrices as functional scaffolds. The biological activity of the peptides was enhanced when the peptides were conjugated to a chitosan matrix, suggesting that the peptide-chitosan matrix approach has an advantage for an active biomaterial. Further, the laminin peptide-chitosan matrices have the potential to mimic the basement membrane and are useful for tissue engineering as an artificial basement membrane.
\end{abstract}

Keywords: basement membrane; laminin; peptides; polysaccharide

\section{Introduction}

Recently, cell-based biomaterials have been found to have therapeutic applications for tissue engineering [1-3]. Epithelial cells form sheet-like complexes in vivo with an underlying thin layer of extracellular matrix (ECM), known as the basement membrane (BM). These complexes are widely 
distributed in the whole body and are an important part of the architecture of many tissues, such as skin, skeletal muscle, nerve, cornea, blood vessel and various glands (Figure 1). In these tissues, epithelial cells adhere to the BMs via more than 20 types of cell surface receptors, including integrins, syndecans, $\alpha$-dystroglycan and the immunoglobulin superfamily [4-6]. BM is comprised of at least four ECM components: type IV collagen, laminin, nidogen and perlecan. Laminin contributes to the biological functions of the BM and plays a critical role for both tissue development and regeneration. Perlecan, a BM proteoglycan, binds and regulates the activity of various growth factors in the BMs. Type IV collagen forms a network structure, and nidogen is a laminin-collagen linker protein. These components form a BM that serves as a functional scaffold for cell attachment and tissue development. Thus, BM provides both a dynamic and static environment for the cells and regulates cell proliferation, migration, differentiation and apoptosis. These activities suggest that optimal BM-mimicking biomaterials should retain biological functions for stimulating cell signaling and the physical functions of the scaffold [7-9].

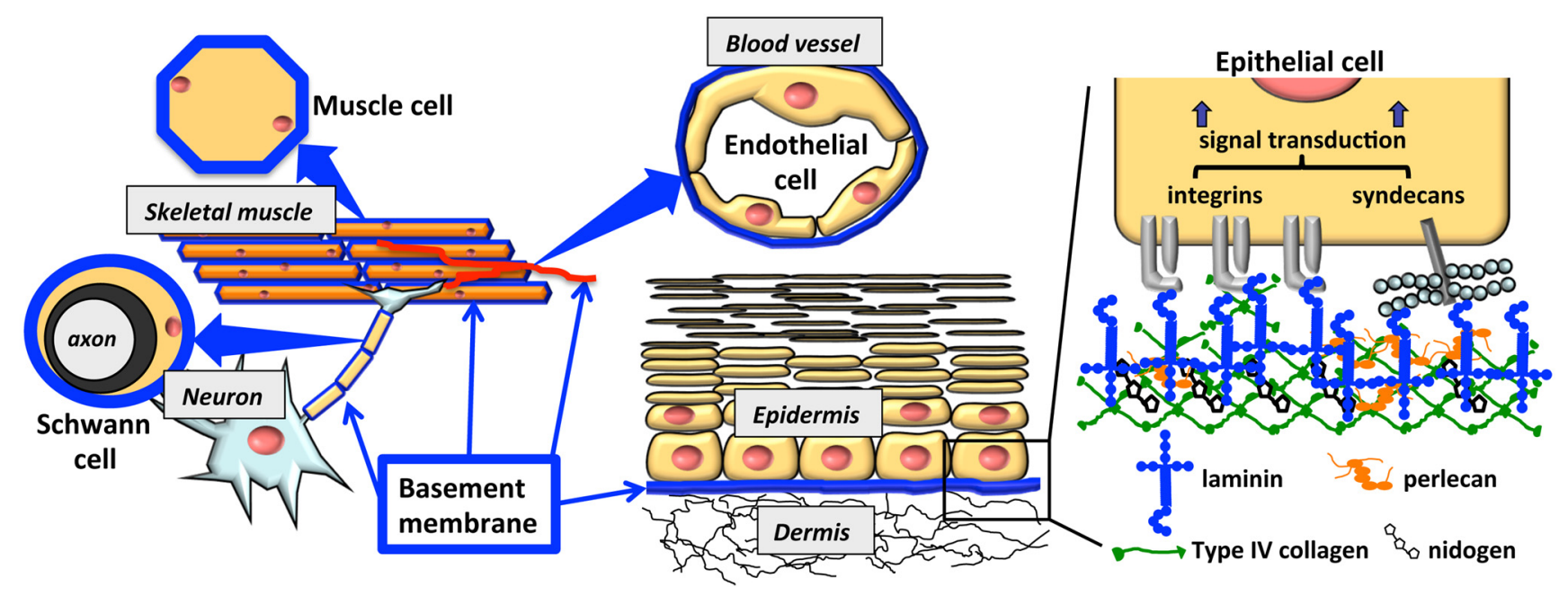

Figure 1. Localization of the BM in the body. BMs are localized in various tissues, such as muscle, nerve, blood vessel and skin.

Laminins, heterotrimeric glycoproteins, consist of $\alpha, \beta$ and $\gamma$ chains. Laminins are the most important molecules of the BMs for cell adhesion. Through cell adhesion to the BMs, laminins promote diverse biological activities, including cell migration, differentiation, neurite outgrowth, tumor growth, tumor metastasis and angiogenesis [10,11]. In vertebrates, five $\alpha$ chains $(\alpha 1-\alpha 5)$, three $\beta$ chains $(\beta 1-\beta 3)$ and three $\gamma$ chains $(\gamma 1-\gamma 3)$ have been identified, and they comprise about 19 different laminin isoforms (laminin-111 to laminin-523) [10-12]. The name of the heterotrimer reflects the chain composition of $\alpha, \beta$ and $\gamma$ chains. For example, laminin-523 consists of $\alpha 5, \beta 2$ and $\gamma 3$ chains. Each laminin isoform is specifically expressed in a tissue- and/or developmental stage-specific manner and promotes laminin isoform-specific functions in optimal situations. The specificity of the laminin $\alpha$ chains mainly contributes to the laminin isoform-specific biological functions. The laminin $\alpha 1$ chain is expressed in the early embryonic BM; the $\alpha 2$ chain is expressed in the BM around muscles and nerves; the $\alpha 3$ chain is localized in epithelial BM; the $\alpha 4$ chain is detected in both the endothelium and smooth muscle BM; and the $\alpha 5$ chain is expressed in diverse adult tissues and in the embryonic BM [13-19]. 
The laminins interact with many types of cell surface receptors [11,20,21]. The major laminin-binding receptor is the integrin family. In total, seven types of integrin are identified as a laminin-binding receptors, and each integrin recognizes specific laminin isoforms. Laminins also bind to syndecans, membrane-associated heparan sulfate proteoglycan, via their heparan sulfate chains [22-26]. Additionally, $\alpha$-dystroglycan binding to the laminin $\alpha 1$ and $\alpha 2$ chains and the Lutheran/basal cell adhesion molecule ( $\mathrm{Lu} / \mathrm{BCAM}$ ) binding to the laminin $\alpha 5$ chain are identified as laminin isoform-specific receptors [12,27-29]. These multiple and diverse cell surface receptors bind to the laminins in different ways depending on the laminin isoforms. Various receptor-specific binding sequences in laminins have been identified in studies using recombinant proteins and synthetic peptides [11,30-36]. The regulation of these laminin-receptor interactions is important for many biological processes. For example, we previously identified about sixty cell-adhesive sequences from laminin-111 using 673 synthetic peptides covering the entire sequence. These active peptides promote various biological activities, including the promotion of cell spreading, cell differentiation, neurite outgrowth, angiogenesis and wound healing, and many of them bind to distinct cellular receptors [32-35,37,38].

Biologically-active scaffolds are important in tissue engineering. Several properties are required for an ideal scaffold, such as a suitable microstructure for the cell, mechanical strength and biocompatibility. So far, many natural polysaccharides, including alginate, cellulose, chitosan, hyaluronan and starch, have been studied for their ability to support the physical environment of the cells. Chitosan, a partially deacetylated chitin, is composed of (1-4)-2-acetoamido-2-deoxy- $\beta$-D-glucan ( $N$-acetyl D-glucosamine) and (1-4)-2-amino-2-deoxy- $\beta$-D-glucan (D-glucosamine) units [39-41]. Chitosan is a biodegradable polysaccharide that has been used for medical applications, such as suture thread and artificial skin, to improve wound healing and to regenerate bones, cartilage, blood vessels and nerves [42-46]. Although the chitosan matrix adheres to tissues, it rarely shows cell attachment through either the growth factor receptors or the adsorbed fibronectin derived from serum [47,48]. Various additions have been proposed, such as a chitosan-collagen (or gelatin) complex [42,49], a chitosan-laminin complex [50], a chitosan-poly lysine complex [51] and cross-linking of cell-adhesive peptides [52,53], to improve the biological activities of the chitosan matrix. Previously, we conjugated laminin-derived cell-adhesive peptides to chitosan, alginate and hyaluronan matrices and examined their biological activities as functional scaffolds [53-64]. For example, we conjugated the laminin $\alpha 1$ chain active peptides, AG73 (RKRLQVQLSIRT, mouse laminin $\alpha 1$ chain) and A99 (AGTFALRGDGNPQ, mouse laminin $\alpha 1$ chain), to a chitosan matrix [53]. AG73 binds to syndecan, and A99 binds to integrin $\alpha v \beta 3$. The AG73-chitosan matrix promoted cell adhesion with membrane ruffling and neurite outgrowth, and the A99-chitosan matrix promoted cell spreading with well-organized actin stress fibers. Further, when the AG73 and A99 peptides were conjugated together to a chitosan matrix with a 1:9 molar ratio, the mixed-peptide chitosan matrix promoted strong cell attachment via the synergistic cooperation of both syndecan and integrin $\alpha v \beta 3$. The mixed peptide-chitosan approach has potential as a multifunctional biomaterial for mimicking the diverse active ECM molecules.

In this paper, we focus on the cell-adhesive laminin-derived peptide conjugated chitosan matrix to mimic the multi-biological functions of BM. We mixed different biologically-active laminin peptides and conjugated the mixtures to a chitosan matrix to optimize the biological activities of the chitosan matrix. The mixed peptide-chitosan matrix significantly enhanced the biological activities via the synergy of these different cell surface receptors. These studies suggest that peptide-conjugated 
chitosan matrices are an ideal biomaterial to develop artificial BMs for therapeutic applications and are useful tools to evaluate cell-ECM interactions.

\section{Cell-Adhesive Peptides from Laminin}

Laminins are multi-functional $\mathrm{BM}$ proteins that contribute to the various biological activities and specificities of the BMs. To identify biologically-active sequences in the laminins, we have systematically screened cell-adhesive sequences using numerous synthetic peptides covering the entire protein sequence. The active peptides identified in the screening of laminin-111 are shown in Figure 2. Peptides were designed generally as 12 amino acids in length, and each peptide overlapped with neighboring peptides by four amino acids. Cysteine residues were omitted. All peptides were manually synthesized by the Fmoc (9-fluorenylmethoxycarbonyl) strategy with a $C$-terminal amide form and purified by HPLC (high performance liquid chromatography). For screening of cell attachment activity, peptide-coated plastic plates and peptide-conjugated Sepharose beads were prepared. The peptide-plate method analyzes the cell attachment activity quantitatively, but the conformation and coating efficiency of the peptides are variable. The peptide-bead method is lacking in quantitative capability, but the conformation and binding efficiency of the peptides are constant. Using these two methods, the cell attachment activity of the peptides is assessed properly. The cell-adhesive peptides were analyzed in detail, and the functional sites of the laminins were identified. So far, more than 100 active peptides have been identified by screening over 2000 peptides from all of the laminin chains. These active peptides were found to interact with cell surface receptors, such as integrins, syndecans, $\alpha$-dystroglycan and CD44, and to promote various biological activities (Table 1).

Table 1. Laminin-derived bioactive peptides, biological activities and receptors.

\begin{tabular}{|c|c|c|c|}
\hline Peptide [Ref No.] & $\begin{array}{l}\text { Sequence } \\
\text { Chain (Residues) }\end{array}$ & Activity & Receptor \\
\hline A13 [33] & $\begin{array}{l}\text { RQVFQVAYIIIKA } \\
\text { mouse laminin } \alpha 1 \text { chain }(121-133)\end{array}$ & $\begin{array}{l}\text { hepatocyte attachment } \\
\text { angiogenesis }\end{array}$ & $\begin{array}{l}\text { syndecan } \\
\text { integrin } \beta 1\end{array}$ \\
\hline A99 [53] & $\begin{array}{l}\text { AGTFALRGDNPQG } \\
\text { mouse laminin } \alpha 1 \text { chain (1141-1153) }\end{array}$ & $\begin{array}{l}\text { cell spreading } \\
\text { neurite outgrowth } \\
\text { metastasis suppression }\end{array}$ & integrin $\alpha v \beta 3$ \\
\hline A208 [65] & $\begin{array}{l}\text { AASIKVAVSADR } \\
\text { mouse laminin } \alpha 1 \text { chain (2121-2132) }\end{array}$ & $\begin{array}{l}\text { fibril formation } \\
\text { neurite outgrowth } \\
\text { MMP } \uparrow\end{array}$ & 110-kDa protein \\
\hline AG73 [24] & $\begin{array}{l}\text { RKRLQVQLSIRT } \\
\text { mouse laminin } \alpha 1 \text { chain }(2719-2730)\end{array}$ & $\begin{array}{l}\text { cell differentiation } \\
\text { neurite outgrowth } \\
\text { wound healing } \\
\end{array}$ & syndecan \\
\hline EF-1 [38] & $\begin{array}{l}\text { DYATLQLQEGRLHFMFDLG } \\
\text { mouse laminin } \alpha 1 \text { chain }(2747-2765)\end{array}$ & cell spreading & integrin $\alpha 2 \beta 1$ \\
\hline C16 [35] & $\begin{array}{l}\text { KAFDITYVRLKF } \\
\text { mouse laminin } \gamma 1 \text { chain }(139-150)\end{array}$ & $\begin{array}{l}\text { MMP } \uparrow \\
\text { angiogenesis }\end{array}$ & unknown \\
\hline A2G10 [66] & $\begin{array}{l}\text { SYWYRIEASRTG } \\
\text { mouse laminin } \alpha 2 \text { chain }(2223-2234)\end{array}$ & cell spreading & integrin $\alpha 6 \beta 1$ \\
\hline
\end{tabular}


Table 1. Cont.

\begin{tabular}{llll}
\hline Peptide [Ref No.] & $\begin{array}{l}\text { Sequence } \\
\text { Chain (Residues) }\end{array}$ & Activity & Receptor \\
\hline A2G78 [29] & $\begin{array}{l}\text { GLLFYMARINHA } \\
\text { mouse laminin } \alpha 2 \text { chain (2796-2807) }\end{array}$ & SMG branching suppression & $\alpha$-dystroglycan \\
\hline A2G80 [29] & $\begin{array}{l}\text { VQLRNGFPYFSY } \\
\text { mouse laminin } \alpha 2 \text { chain (2812-2823) }\end{array}$ & SMG branching suppression & $\alpha$-dystroglycan \\
\hline A3G756 [22] & $\begin{array}{l}\text { KNSFMALYLSKGRLVFALG } \\
\text { human laminin } \alpha 3 \text { chain (1411-1429) }\end{array}$ & wound healing & syndecans \\
\hline A5G27 [67] & $\begin{array}{l}\text { RLVSYNGIIFFLK } \\
\text { mouse laminin } \alpha 5 \text { chain (2892-2904) }\end{array}$ & metastasis suppression & CD44 \\
\hline
\end{tabular}

MMP $\uparrow$, matrix metalloproteinase promotion; SMG, mouse submandibular gland.

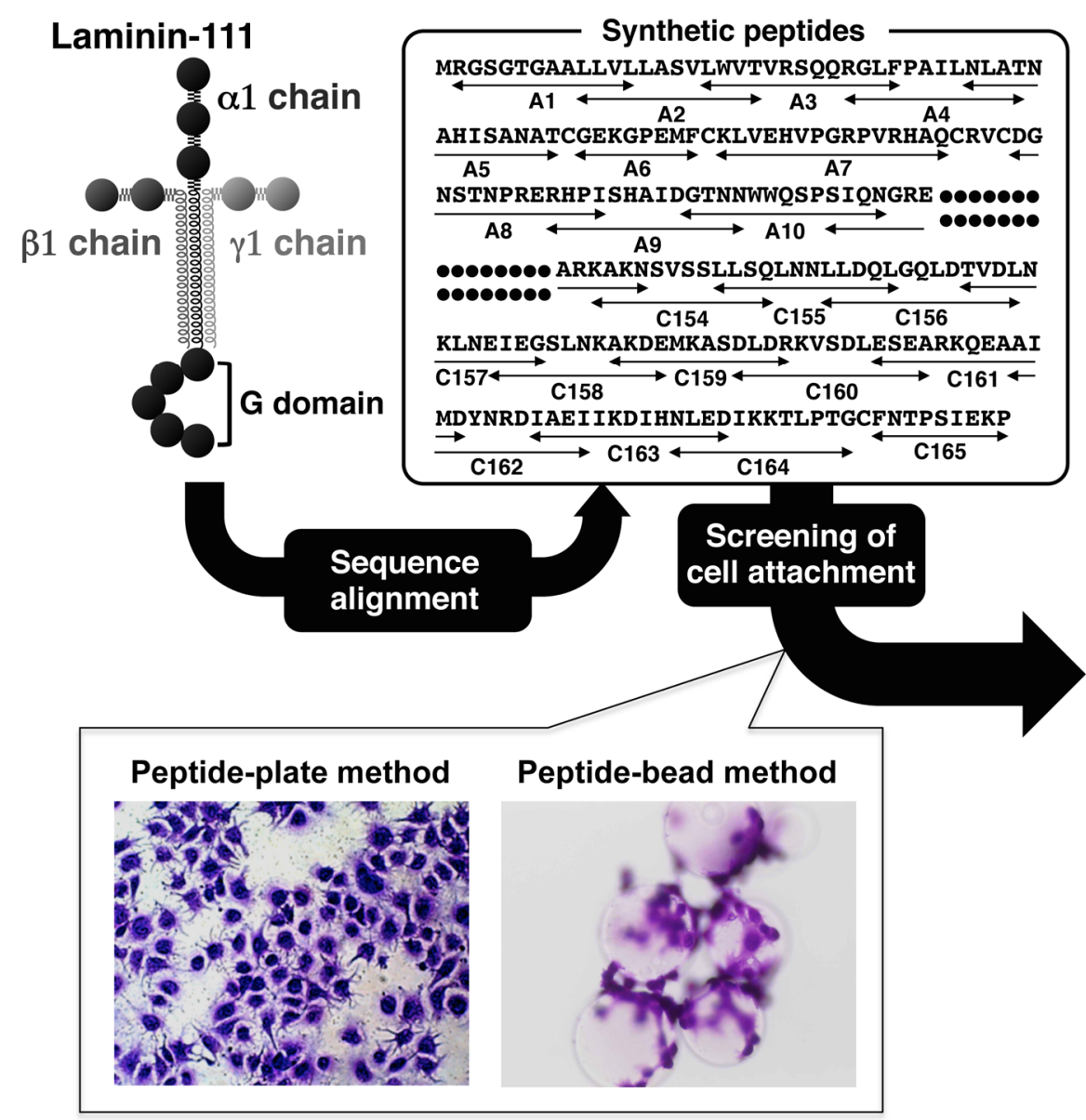

\begin{tabular}{|c|c|}
\hline $\begin{array}{l}\text { Active } \\
\text { peptide }\end{array}$ & Sequence \\
\hline A10 & GTNNWWQSPSIQN \\
\hline A13 & RQVFQVAYIIIKA \\
\hline A24 & LLEFTSARYIRL \\
\hline A51 & SINNTAVMQRLT \\
\hline A64 & RDQLMTVLANVT \\
\hline A99 & AGTFALRGDNPQG \\
\hline A119 & LSNIDYILIKAS \\
\hline A167 & NLLLLLLVKANLK \\
\hline A208 & AASIKVAVSADR \\
\hline AG10 & NRWHS IY ITRFG \\
\hline AG32 & TWYKIAFQRNRK \\
\hline AG73 & RKRLQVQLSIRT \\
\hline EF1 & DYATLQLQEGRLHFMFDLG \\
\hline B30 & RIQNLLKITNLR \\
\hline B54 & KRLVTGQR \\
\hline B133 & DSITKYFQMSLE \\
\hline B160 & VILQQSAADIAR \\
\hline C16 & KAFDITYVRLKF \\
\hline $\mathrm{C} 28$ & TDIRVTLNRLNTF \\
\hline C64 & SETTVKYIFRLHE \\
\hline C68 & TSIKIRGTYSER \\
\hline
\end{tabular}

Figure 2. Screening of cell-adhesive peptides from laminin-111. Peptides were generally 12 amino acids in length and overlapped with neighboring peptides by four amino acids. Cysteine residues were omitted. All peptides were manually synthesized by the Fmoc strategy with a $C$-terminal form and were purified by HPLC. For screening of cell attachment activity, peptide-coated plastic plates and peptide-conjugated Sepharose beads were used. Major cell-adhesive peptides are listed on the right side. (Adapted with permission from [57], copyright 2011 Wiley). 
For example, peptide AG73 (RKRLQVQLSIRT, mouse laminin $\alpha 1$ chain) promoted strong cell attachment, neurite outgrowth, salivary gland acini-like differentiation and angiogenesis $[24,32,33,68]$. Peptide A99 (AGTFALRGDGNPQ, mouse laminin $\alpha 1$ chain) promoted cell attachment and cell spreading [33]. Peptide A2G80 (VQLRNGFPYFSY, mouse laminin $\alpha 2$ chain) is $\alpha$-dystroglycan-binding site in the laminin $\alpha 2$ chain LG4-5 module [29]. Peptide A3G756 (KNSFMALYLSKGRLVFALG, human laminin $\alpha 3$ chain) binds to syndecans and promotes wound healing in vivo [22]. Peptide A5G27 (RLVSYNGIIFFLK, mouse laminin $\alpha 5$ chain) binds to the CD44 receptor on B16-F10 melanoma cells and, thus, inhibits tumor cell migration, invasion and angiogenesis in a dominant-negative manner [67,69]. Here, we used these unique active laminin-derived peptides as both adhesion agents and functional regulators for multifunctional cell scaffolds, which we term artificial BMs. These peptide-chitosan complexes have potential application in tissue engineering as artificial BMs.

\section{Preparation of Peptide-Chitosan Matrices}

Cells cannot adhere to chitosan in serum-free condition. Therefore, the laminin active peptides were conjugated to chitosan to provide the specific and cell surface receptor-mediated cell attachment activities to the chitosan matrix (Figure 3) [53,57]. Chitosan (chitosan 10, deacetylation rate: $\mathrm{min} .80 .0 \mathrm{~mol} / \mathrm{mol} \%$, Wako Pure Chemical, Osaka, Japan) was dissolved in DMF ( $N, N$-dimethylformamide) solution ( $2 \%$ aqueous AcOH-DMF 3:1, v/v) and reacted with $N$-( $m$-maleimidebenzoyloxy) succinimide (MBS). As a result, maleimidebenzoyloxy (MB)-chitosan was obtained, and the substitution ratio of the MB groups to the chitosan is about $1 \%-1.2 \%$ /sugar unit. MB-chitosan in $4 \% \mathrm{AcOH}$ solution was added to the plates and dried for 2 days to coat the plates, and then, the plates were treated with $1 \% \mathrm{NaHCO}_{3}$ solution to fix the chitosan. For conjugation of the peptides to MB-chitosan, we synthesized CGG-peptides. Cysteine (C) residue at the $N$-terminus was covalently bound to the MB group via a mercapto group. Two glycine $(\mathrm{G})$ residues were used as a spacer between the cysteine and the active peptide sequence. Almost a 10- to 100-times excess amount of CGG-peptide (against MB groups in chitosan) solution in $0.1 \%$ TFA (Trifluoroacetic acid) was added to the MB-chitosan matrix-coated plates, and an equal volume of $1 \% \mathrm{NaHCO}_{3}$ solution was added to neutralize and promote peptide conjugation. The peptide-chitosan matrix was washed with PBS (Phosphate bufferd saline) 2 times and then with $0.1 \%$ BSA (Bovine serum albumin) containing DMEM (Dulbecco's modified essential medium) 2 times. After washing, the peptide-chitosan matrices were blocked with 1\% BSA in DMEM for $1 \mathrm{~h}$ and assessed for their biological activities using various cell lines and assays.

\section{Biological Functions of Peptide-Polysaccharide Complexes}

The cellular activities on these peptide-chitosan matrices were analyzed. In cell attachment assays under serum-free conditions, we found that chitosan with the conjugated active peptides enhanced cell attachment activity. The number of attached cells on the complexes depended on the amount of the reacted peptides and was higher than that on the peptide-coated plastic substrates $[53,68]$. These results suggest that the chitosan matrix is a compatible scaffold for the cells and that the peptides conjugated to the matrices have an active conformation. Furthermore, the peptide-chitosan matrices promoted neurite outgrowth of rat pheochromocytoma PC12 cells, suggesting that the complexes can also 
regulate cell differentiation, similar to the activity of the intact BM. Additionally, the cells showed different morphologies on each peptide (Figure 4). Human dermal fibroblasts (HDFs) strongly spread on both A99a (a minimum sequence of A99, ALRGDN) and EF1zz (a modified peptide of EF-1, ATLQLQEGRLHFXFDLGKGR, X: Nle (Norleucine), mouse laminin $\alpha 1$ chain, binds to integrin a2ß1)-chitosan matrix, with typical fibroblast-type actin stress fibers, whereas the AG73-chitosan matrix induced the formation of actin filament spikes associated with membrane ruffles [25,54]. Because cellular behavior occurs via the interaction between the adhesion factor and the cell surface receptors, these cell morphological differences are due to specific peptide binding to the receptors. In the peptide-chitosan matrix, chitosan acts as a physical support, and the peptides bind to cells via cell surface receptors. The laminin-derived active peptide conjugated chitosan matrices can control receptor-type-specific functions and are useful in tissue engineering.

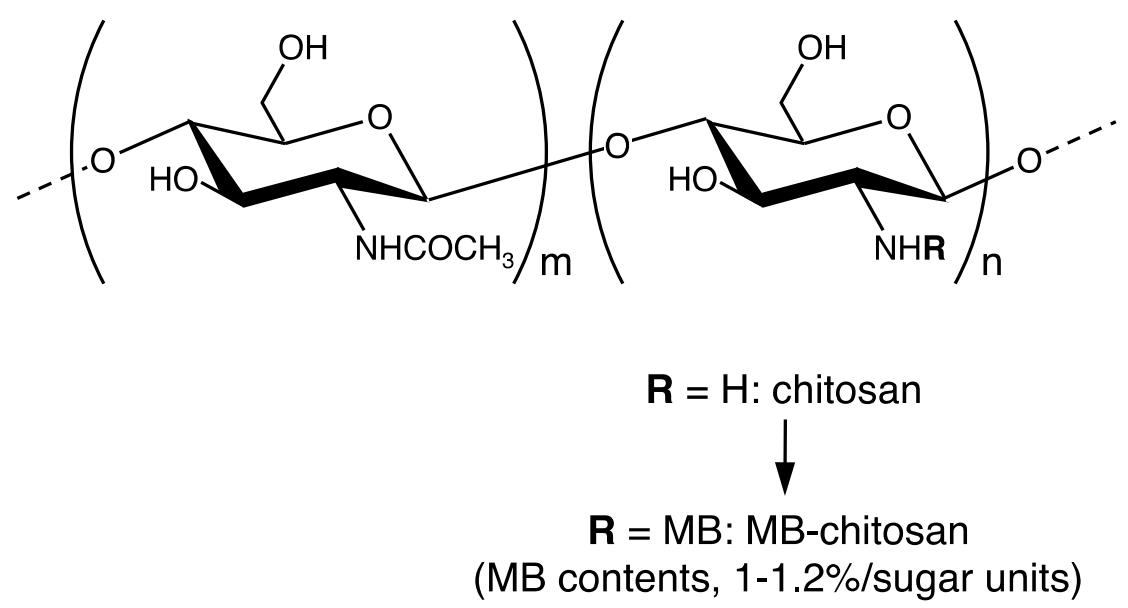

Figure 3. MB-chitosan synthesis. Chitosan was reacted with MBS ( $N$-( $m$-maleimidebenzoyloxy) succinic-imide) in DMF solution. Maleimidebenzoyloxy (MB)-chitosan was obtained, and the substitution ratio of MB groups to the chitosan is about $1 \%-1.2 \%$ /sugar unit.
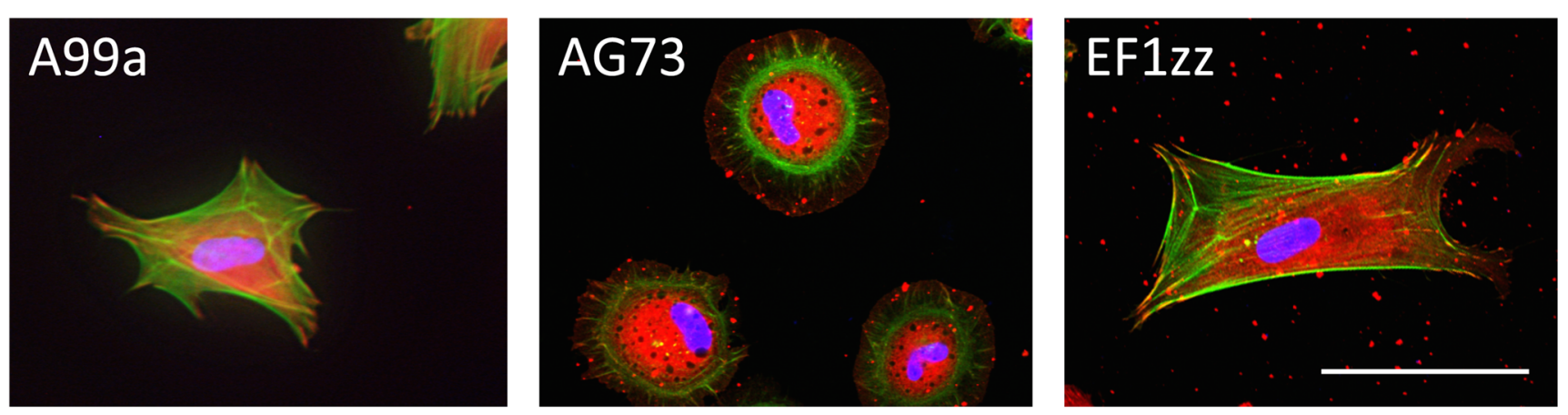

Figure 4. Cell morphology on peptide-chitosan matrices. CGG-A99a, CGG-AG73 and CGG-EF1zz were coupled to the MB-chitosan matrices ( $2 \mathrm{nmol} /$ well) in 96-well plates. Human dermal fibroblasts (HDFs) were allowed to attach to the peptide-chitosan matrices for $2 \mathrm{~h}$, and then, actin (green), vinculin (red) and the nucleus (blue) were observed by specific immunostaining. Scale bar $=50 \mu \mathrm{m}$. 


\section{Mixed Peptide-Chitosan Matrices Mimic the Multifunctions of Laminins}

Our research is aimed at the identification of the synergistic effects via different cell surface receptors and replication of $\mathrm{BM}$ molecular functions using mixed peptide-chitosan matrices. At first, we focused on the LG4 module at the $C$-terminus of the laminin $\alpha 1$ chain as a targeted multifunctional $\mathrm{BM}$ molecule and tried to mimic the full function using a mixed peptide-chitosan matrix approach [61]. The LG4 module interacts with both syndecan and integrin $\alpha 2 \beta 1$ via the AG73 and EF-1 sites, respectively, and strongly promotes cell attachment and spreading [25]. Thus, we covalently conjugated the AG73 and EF1zz peptides to a chitosan matrix with various ratios (molar ratio = 1:0, 9:1, $4: 1,1: 1,1: 4,1: 9,0: 1)$ and compared their biological activities with that of the recombinant LG4 module protein (rec-LG4). The cell attachment activity and cell morphology depended on the ratios of the syndecan- and integrin $\alpha 2 \beta 1$-binding peptides on the chitosan matrix (Figure 5). The AG73/EF1zz (molar ratio $=1: 9)$-chitosan matrix strongly promoted HDF attachment, spreading and neurite outgrowth, similar to that on the rec-LG4 protein. It is reported that cell adhesion to the ECM is promoted by synergistic signaling between syndecans and integrins [61,70]. We found that the AG73/EF1zz (molar ratio = 1:9)-chitosan matrix contains an optimal peptide ratio for the synergistic effect of syndecan- and integrin $\alpha 2 \beta 1$ - mediated cell attachment. These results suggest that the AG73/EF1zz-chitosan matrix interacts with both syndecans and $\alpha 2 \beta 1$ integrin and mimics the multifunctional activity of the LG4 protein.
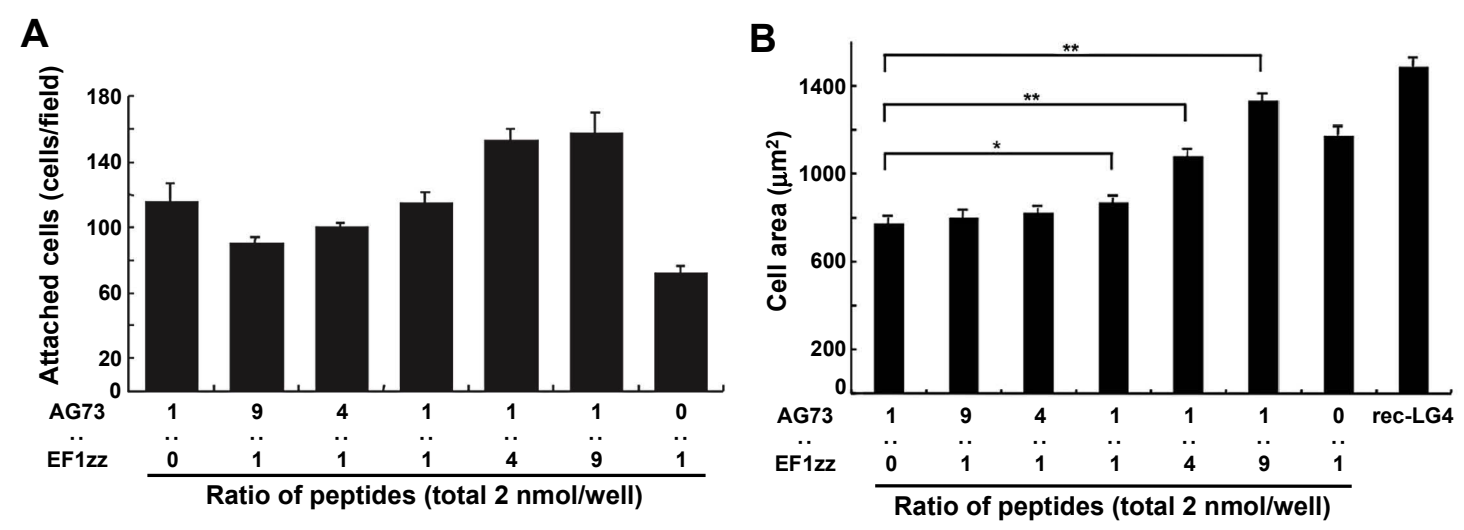

Figure 5. Cell attachment and spreading activity of mixed peptide-chitosan matrices. (A) CGG-AG73 and CGG-EF1zz peptides, both derived from the laminin $\alpha 1$ chain LG4 globular module, were mixed in various ratios and were coupled to the MB-chitosan matrices ( $2 \mathrm{nmol} /$ well) in 96-well plates. HDFs were allowed to attach to the mixed peptide-chitosan matrices for $2 \mathrm{~h}$. The attached HDFs in three randomly-selected fields $\left(0.3 \mathrm{~mm}^{2}\right)$ were counted. Each value represents the mean \pm SD of triplicate experiments; (B) HDFs were allowed to attach to either a rec-LG4 (3 mg/well of protein solution was incubated overnight)-coated plate or $2 \mathrm{nmol}$ peptide-chitosan matrices for $2 \mathrm{~h}$. Cell images were captured, and the area of the attached cells was measured. Each value represents the mean \pm SD of triplicate experiments. The AG73/EF1zz (1:9)-chitosan matrix promoted the strongest cell attachment and most extensive cell spreading comparable with that of rec-LG4. * $p<$ $0.05, * * p<0.005$. (Adapted with permission from [61], copyright 2009 Elsevier). 
Next, we focused on laminin-111 and mimicked its multifunctional activity using multipeptide-chitosan matrices [60]. Previously, we identified sixty biologically-active peptides in the laminin-111 sequence by a systematic peptide screening. At first, we constructed sixty peptide-chitosan matrices using these active peptides. Twenty-nine peptide-chitosan matrices promoted various biological activities, including cell attachment, spreading and neurite outgrowth. The biological activities of the peptide-chitosan matrices depended on the peptide. We classified the twenty-nine biologically-active peptides into six categories that indicated different biological activities based on HDF attachment, cell surface receptors and PC12 (rat pheochromocytoma) neurite outgrowth activities (Table 2). Five HDF-adhesive peptides, including A99a (Group 1), EF1zz (Group 2), C16 (Group 3, KAFDITYVRLKF, mouse laminin $\gamma 1$ chain), C68 (Group 4, TSIKIRGTYSER, mouse laminin $\gamma 1$ chain) and B31 (Group 5, TNLRIKFVKLHT, mouse laminin $\beta 1$ chain), which showed the strongest activity in each category, were mixed in equal amounts and conjugated onto a chitosan matrix to evaluate their synergistic activity (Figure 6). The multipeptide-chitosan matrix significantly accelerated HDF attachment and cell spreading over that observed with any individual peptide. These results suggest that the five peptides cooperate and promote synergistic activity. We also mixed four neurite outgrowth-active peptides from each group, including A99a (Group 1), C16 (Group 3), B31 (Group 5) and A1 12 (Group 6, VLIKGGRARKHV, mouse laminin $\alpha 1$ chain) and prepared a multipeptide-chitosan matrix for neurite outgrowth. The multipeptide-chitosan matrix showed stronger neurite outgrowth activity compared with that observed on each individual peptide-chitosan matrix. The neurites on each single peptide-chitosan matrix were relatively short, wide and curved. In contrast, neurites on the multipeptide-chitosan matrix and laminin-111 were long, thin and linear. These results suggest that a synergistic cooperation among the different cell surface receptors occurred on the multipeptide matrices and that the multipeptide-chitosan matrices represent laminin-like activity.

Since cell morphology, migration and stem cell differentiation are regulated by the rigidity of the scaffold, mechanosensing by the cells is important in cell-based tissue engineering. Optimization of the scaffold stiffness has been noted as one of the bioengineering parameters to regulate cellular functions. We determined whether the density of the chitosan scaffold altered the cellular response [54,57]. When peptide A99a (binds to integrin $\alpha v \beta 3$ ) was conjugated to chitosan matrices of varying density (1.5-1500 $\mathrm{ng} / \mathrm{mm}^{2}$ ), HDF adhesion was altered depending on the amount of chitosan (Figure 7). We found that $1.5-30 \mathrm{ng} / \mathrm{mm}^{2}$ of the A99a-chitosan matrix effectively promoted HDF attachment, cell spreading with well-organized actin stress fibers, Tyr397 phosphorylation of FAK (focal adhesion kinase) and neurite outgrowth. In contrast, the AG73 (binds to syndecan)-chitosan matrix density $\left(1.5-1500 \mathrm{ng} / \mathrm{mm}^{2}\right)$ promoted similar biological activities at all of the concentrations tested. These results suggest that cell adhesion is sensitive to the scaffold density and depends on the cell surface receptors. To improve the function of integrin-mediated biological activities on a large amount of scaffold (150-1500 $\mathrm{ng} / \mathrm{mm}^{2}$ ), we designed an A99a/AG73 mixed peptide-chitosan matrix [54]. The mixed peptide-chitosan matrix promoted the strongest biological activity at $150-1500 \mathrm{ng} / \mathrm{mm}^{2}$ of chitosan matrix. We conclude that the A99a/AG73 mixed peptide-chitosan matrix effectively interacts with both integrins and syndecans, regardless of the amount and stiffness of the chitosan matrix. 

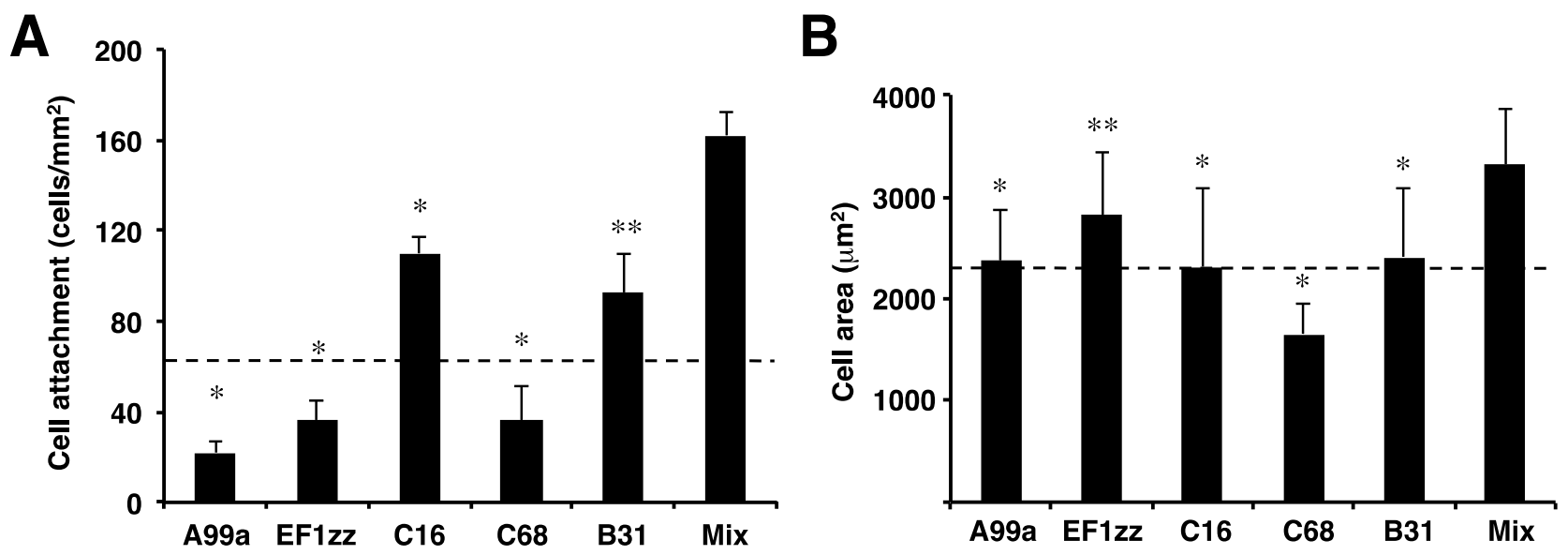

Figure 6. Cell attachment and spreading activity of multipeptide-chitosan matrices mimicking laminin-111. CGG-A99a, CGG-EF1zz, CGG-C16, CGG-C68 and CGG-B31 (derived from laminin-111, $10 \mathrm{nmol} /$ well), both individually and as a five-peptide mixture (mix; $10 \mathrm{nmol} /$ well; $2 \mathrm{nmol}$ each) of peptides, were coupled to the MB-chitosan matrices in 96-well plates. (A) HDFs were allowed to attach to the peptide and mixed peptide-chitosan matrices for $2 \mathrm{~h}$. The attached cells in three randomly-selected fields were counted. Each value represents the mean \pm SD of triplicate experiments. ${ }^{*} p<0.05,{ }^{* *} p<0.005$; (B) Cell areas on the various chitosan matrices were measured using ImageJ. The mixed-peptide-chitosan matrix promoted the most extensive cell spreading. (Adapted with permission from [60], copyright 2012 Elsevier).

Table 2. Twenty nine peptide-chitosan membranes could be divided into six categories depending on their biological activities.

\begin{tabular}{|c|c|c|c|c|c|c|c|}
\hline \multirow{3}{*}{ Group } & \multicolumn{5}{|c|}{ Biological Activities on HDFs } & \multirow{3}{*}{$\begin{array}{c}\text { Neurite } \\
\text { Outgrowth } \\
\text { Activity on } \\
\text { PC12 cells } \\
\end{array}$} & \multirow{3}{*}{ Peptides } \\
\hline & \multirow{2}{*}{$\begin{array}{c}\text { HDF } \\
\text { Attachment }\end{array}$} & \multirow{2}{*}{$\begin{array}{c}\text { HDF } \\
\text { Spreading }\end{array}$} & \multicolumn{2}{|c|}{$\begin{array}{c}\text { Inhibitory Effect } \\
\text { on HDF Attachment }\end{array}$} & \multirow{2}{*}{$\begin{array}{c}\text { Predicted Cell } \\
\text { Surface Receptors }\end{array}$} & & \\
\hline & & & EDTA & Heparin & & & \\
\hline 1 & + & $\mathrm{S}$ & + & - & Integrin & + & A99a \\
\hline 2 & + & $\mathrm{S}$ & + & - & Integrin & - & EF1zz \\
\hline 3 & + & $\mathrm{s}$ & + & + & Integrin/syndecan & + & $\begin{array}{c}\text { A13, AG32, AG103, } \\
\text { C16, C57, C64 }\end{array}$ \\
\hline 4 & + & $\mathrm{s}$ & + & + & Integrin/syndecan & - & $\begin{array}{c}\text { A3, A55, A65, A119, } \\
\text { A167, A174, AG10, } \\
\text { AG28, AG56, B30, } \\
\text { B133, B160, C59, C68 }\end{array}$ \\
\hline 5 & + & $\mathrm{w}$ & - & + & Syndecan & + & A206, AG73, B20, B31 \\
\hline 6 & - & - & - & - & - & + & A25, A112, A194 \\
\hline
\end{tabular}

HDF spreading: S, extended spreading; s, moderate spreading; w, wide and round spreading. Biological activities of HDF attachment and Neurite outgrowth indicate as + (active) or - (inactive). Inhibitory effect of EDTA or heparin on HDF attachment indicate as + (reduce attachment) or - (no change). (Adapted with permission from [60], copyright 2012 Elsevier). 
A
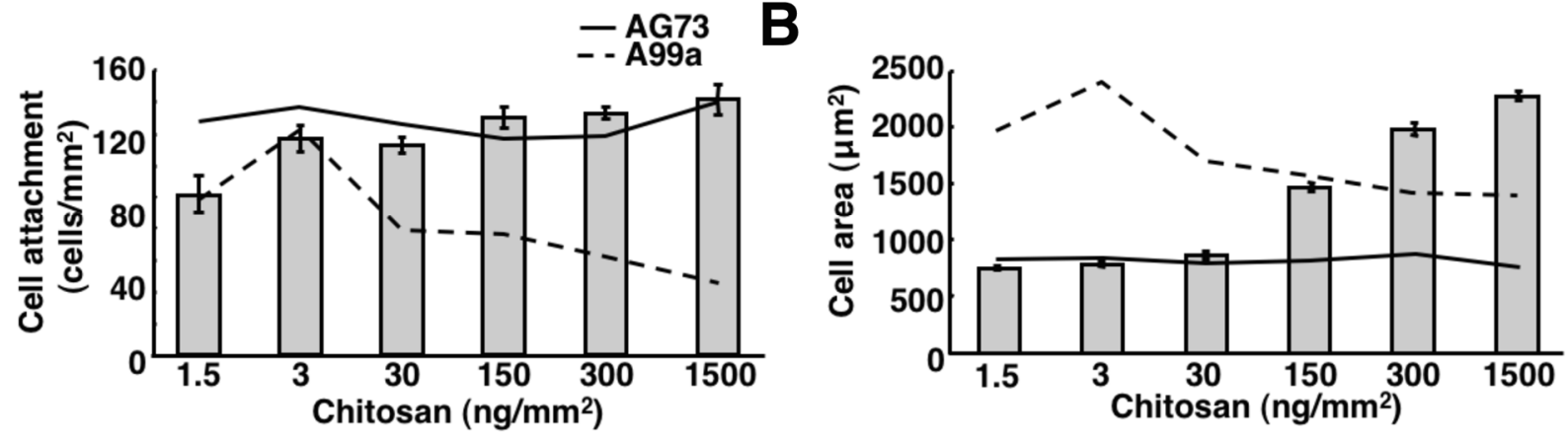

Figure 7. The density of chitosan affects the cell attachment and spreading activity of mixed peptide-chitosan matrices. The different concentrations of the MB-chitosan solutions were dried in the 96-well plates, and various densities of MB-chitosan matrices $\left(1.5-1500 \mathrm{ng} / \mathrm{mm}^{2}\right)$ were prepared. Excess amounts of CGG-A99a, CGG-AG73 (50 nmol/well) and CGG-A99a:CGG-AG73 = 9:1 (A99a, $45 \mathrm{nmol} / \mathrm{well} ;$ AG73, $5 \mathrm{nmol} /$ well) peptide solutions were added to the MB-chitosan matrices in each well and conjugated. (A) HDFs were allowed to attach to the peptide-chitosan matrices for $2 \mathrm{~h}$. The attached cells in three randomly-selected fields were counted; (B) cell images were captured, and the area of the attached cells was measured. In each graph, the results of AG73-chitosan matrices (solid line) and A99a-chitosan matrices (dotted line) are shown. The experiments were done three times with similar results. The AG73/A99a (1:9)-chitosan matrix promoted the strongest cell attachment and spreading activities at the high densities of the chitosan matrix $\left(150-1500 \mathrm{ng} / \mathrm{mm}^{2}\right.$ ). (Adapted with permission from [54], copyright 2010 Elsevier).

The receptor-specific peptides have various advantages and are a powerful tool for evaluating the mechanism of the multi-receptor interactions, including cell-ECM interactions. Based on these results, we conclude that the mixed peptide-chitosan matrix using different receptor-binding peptides can elicit simultaneous cellular interactions and could reproduce the BM molecular functions. We believe that this approach is a useful strategy to mimic the BM.

\section{Application of Peptide-Chitosan Matrices to Cell Transplantation}

Cell transplantation is a medical procedure that can be an application for tissue engineering. We examined whether peptide-chitosan matrices are a suitable scaffold material for cell-transplantation to wounded tissue in vivo (Figure 8) [62,71]. We seeded human keratinocyte onto AG73-chitosan matrices and found that nearly $80 \%$ of the cells were attached to the matrices within $2 \mathrm{~h}$. The matrix with keratinocyte was then inverted onto the muscular fascia (an artificial "wound bed") exposed on the back of a nude mouse, and the skin flap was sutured to protect the graft. A silicon mesh was inserted between the matrix and the skin flap to prevent the growth of host keratinocytes into the wound bed. After three days, the human keratinocytes had migrated from the chitosan matrix and established a stratified epidermis-like structure on the mouse fascia. Further, the transplanted cells expressed various keratinocyte markers, including cytekeratin-1, involucrin and laminin $\gamma 2$ chain, suggesting that the transplanted cells were undergoing cytodifferentiation resembling the epidermis. 
The peptide-chitosan matrix is easy to handle. Therefore, the peptide-chitosan matrix system is an alternative and potentially powerful tool for keratinocyte delivery to the wound bed. In conclusion, the peptide-chitosan matrices may be a new and broadly applicable tool for cell transplantation to damaged tissues.
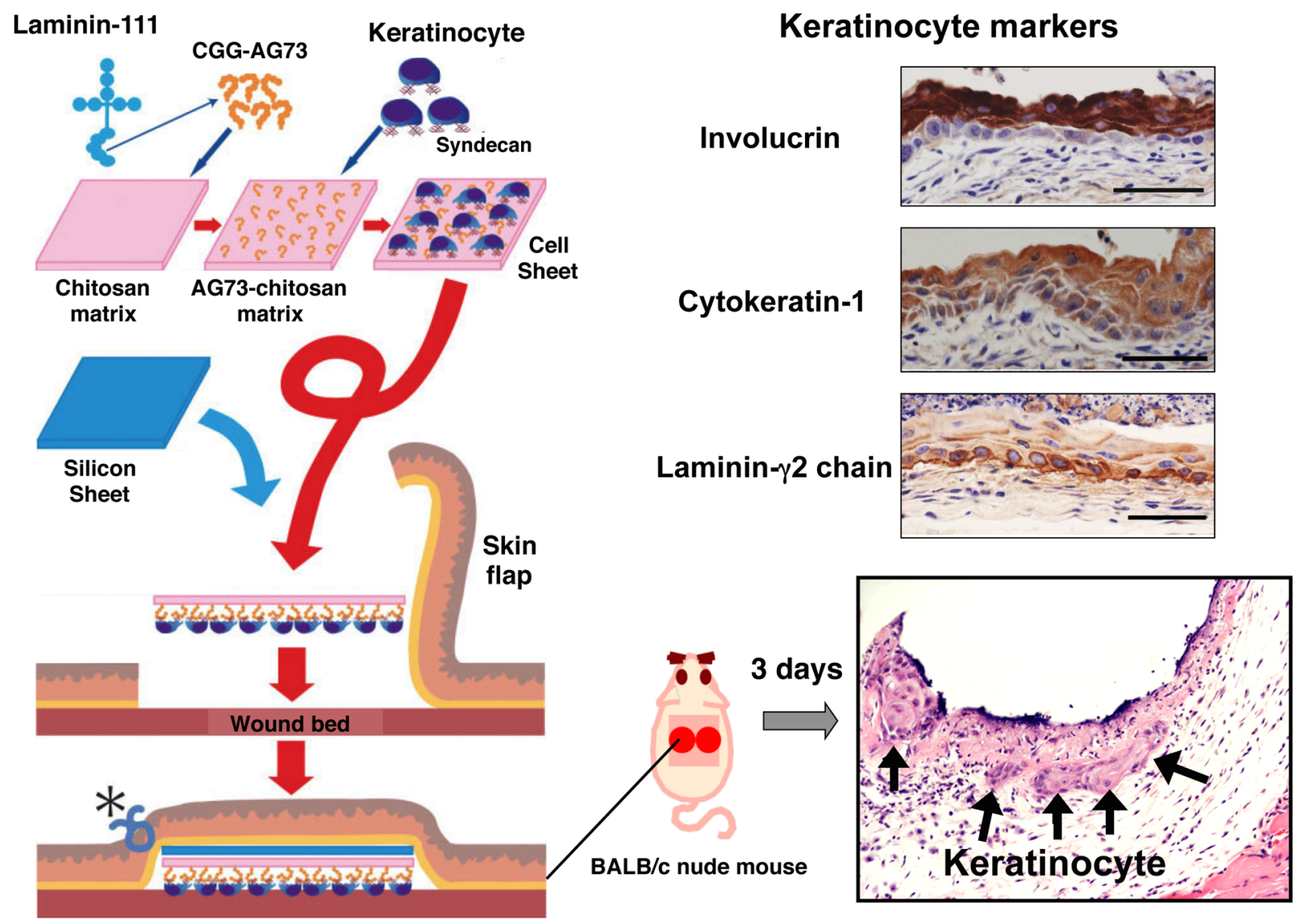

Figure 8. Schematic representation of keratinocyte transplantation using an AG73-chitosan matrix. Keratinocytes were seeded onto an AG73-chitosan matrix and cultured for $2 \mathrm{~h}$. The cell sheet with keratinocytes was then inverted onto the muscular fascia (an artificial "wound bed") exposed on the back of nude mice, and the skin flap was sutured (asterisk) to protect the graft. A silicon sheet was inserted between the cell sheet and the skin flap to prevent the growth of host keratinocytes into the wound bed. After three days, the expression of various keratinocyte markers, including involucrin, cytokeratin and laminin- $\gamma 2$, was observed in the cell sheet. Scale bars $=50 \mathrm{~mm}$. (Adapted with permission from [62], copyright 2006 Wiley).

\section{Summary and Outlook}

In summary, the peptide-conjugated chitosan matrices specifically interact with cellular receptors and promote various biological activities, including cell attachment, spreading and neurite outgrowth. The mixed peptide-chitosan matrix approach using receptor-specific peptides can reproduce the multi-receptor interactions and enhance the biological activities with their synergistic effects. Further, the peptide-chitosan matrices can be used as a biomaterial for both cell transplantation and tissue engineering. The peptide-chitosan matrices have potential for use as an artificial BM. 


\section{Acknowledgments}

We are grateful to Yamato Kikkawa, Fumihiko Katagiri and Yuichi Kadoya for invaluable comments and suggestions. This work was supported by Grants-in-Aid for Scientific Research from the Ministry of Education, Cultures, Sports, Science and Technology of Japan (24500530 and 25560228).

\section{Author Contributions}

Kentaro Hozumi designed and supervised the experimental work and wrote the manuscript. Jun Kumai and Yuji Yamada co-designed, and conducted experiments, and co-authored the manuscript. Motoyoshi Nomizu supervised the research project.

\section{Conflicts of Interest}

The authors declare no conflict of interest.

\section{References}

1. Dieckmann, C.; Renner, R.; Milkova, L.; Simon, J.C. Regenerative medicine in dermatology: Biomaterials, tissue engineering, stem cells, gene transfer and beyond. Exp. Dermatol. 2010, 19, 697-706.

2. Fox, I.J.; Daley, G.Q.; Goldman, S.A.; Huard, J.; Kamp, T.J.; Trucco, M. Stem cell therapy. Use of differentiated pluripotent stem cells as replacement therapy for treating disease. Science 2014, 345, doi:10.1126/science.1247391.

3. Tuan, R.S. Regenerative medicine in 2012: The coming of age of musculoskeletal tissue engineering. Nat. Rev. Rheumatol. 2013, 9, 74-76.

4. Kruegel, J.; Miosge, N. Basement membrane components are key players in specialized extracellular matrices. Cell. Mol. Life Sci. 2010, 67, 2879-2895.

5. Frantz, C.; Stewart, K.M.; Weaver, V.M. The extracellular matrix at a glance. J. Cell Sci. 2010, 123, 4195-4200.

6. Wiradjaja, F.; DiTommaso, T.; Smyth, I. Basement membranes in development and disease. Birth Defects Res. C Embryo Today Rev. 2010, 90, 8-31.

7. Brown, B.N.; Badylak, S.F. Extracellular matrix as an inductive scaffold for functional tissue reconstruction. Transl. Res. J. Lab. Clin. Med. 2014, 163, 268-285.

8. Lutolf, M.P.; Hubbell, J.A. Synthetic biomaterials as instructive extracellular microenvironments for morphogenesis in tissue engineering. Nat. Biotechnol. 2005, 23, 47-55.

9. Renner, L.; Jorgensen, B.; Markowski, M.; Salchert, K.; Werner, C.; Pompe, T. Control of fibronectin displacement on polymer substrates to influence endothelial cell behaviour. J. Mater. Sci. Mater. Med. 2004, 15, 387-390.

10. Patarroyo, M.; Tryggvason, K.; Virtanen, I. Laminin isoforms in tumor invasion, angiogenesis and metastasis. Semin. Cancer Biol. 2002, 12, 197-207.

11. Miner, J.H.; Yurchenco, P.D. Laminin functions in tissue morphogenesis. Annu. Rev. Cell Dev. Biol. 2004, 20, 255-284. 
12. Scheele, S.; Nystrom, A.; Durbeej, M.; Talts, J.F.; Ekblom, M.; Ekblom, P. Laminin isoforms in development and disease. J. Mol. Med. 2007, 85, 825-836.

13. Miyagoe, Y.; Hanaoka, K.; Nonaka, I.; Hayasaka, M.; Nabeshima, Y.; Arahata, K.; Nabeshima, Y.; Takeda, S. Laminin $\alpha 2$ chain-null mutant mice by targeted disruption of the Lama2 gene: A new model of merosin (laminin 2)-deficient congenital muscular dystrophy. FEBS Lett. 1997, 415, $33-39$.

14. Thyboll, J.; Kortesmaa, J.; Cao, R.; Soininen, R.; Wang, L.; Iivanainen, A.; Sorokin, L.; Risling, M.; Cao, Y.; Tryggvason, K. Deletion of the laminin $\alpha 4$ chain leads to impaired microvessel maturation. Mol. Cell. Biol. 2002, 22, 1194-1202.

15. Kuang, W.; Xu, H.; Vachon, P.H.; Engvall, E. Disruption of the Lama2 gene in embryonic stem cells: Laminin $\alpha 2$ is necessary for sustenance of mature muscle cells. Exp. Cell Res. 1998, 241, 117-125.

16. Miner, J.H.; Cunningham, J.; Sanes, J.R. Roles for laminin in embryogenesis: Exencephaly, syndactyly, and placentopathy in mice lacking the laminin $\alpha 5$ chain. J. Cell Biol. 1998, 143, 1713-1723.

17. Ryan, M.C.; Lee, K.; Miyashita, Y.; Carter, W.G. Targeted disruption of the Lama3 gene in mice reveals abnormalities in survival and late stage differentiation of epithelial cells. J. Cell Biol. 1999, 145, 1309-1324.

18. Miner, J.H.; Li, C.; Mudd, J.L.; Go, G.; Sutherland, A.E. Compositional and structural requirements for laminin and basement membranes during mouse embryo implantation and gastrulation. Development 2004, 131, 2247-2256.

19. Wang, J.; Hoshijima, M.; Lam, J.; Zhou, Z.; Jokiel, A.; Dalton, N.D.; Hultenby, K.; Ruiz-Lozano, P.; Ross, J., Jr.; Tryggvason, K.; et al. Cardiomyopathy associated with microcirculation dysfunction in laminin $\alpha 4$ chain-deficient mice. J. Biol. Chem. 2006, 281, 213-220.

20. Hood, J.D.; Cheresh, D.A. Role of integrins in cell invasion and migration. Nat. Rev. Cancer 2002, 2, 91-100.

21. Kikkawa, Y.; Hozumi, K.; Katagiri, F.; Nomizu, M.; Kleinman, H.K.; Koblinski, J.E. Laminin-111-derived peptides and cancer. Cell Adhes. Migr. 2013, 7, 150-256.

22. Araki, E.; Momota, Y.; Togo, T.; Tanioka, M.; Hozumi, K.; Nomizu, M.; Miyachi, Y.; Utani, A. Clustering of syndecan-4 and integrin $\beta 1$ by laminin $\alpha 3$ chain-derived peptide promotes keratinocyte migration. Mol. Biol. Cell 2009, 20, 3012-3024.

23. Couchman, J.R.; Chen, L.; Woods, A. Syndecans and cell adhesion. Int. Rev. Cytol. 2001, 207, $113-150$.

24. Hoffman, M.P.; Nomizu, M.; Roque, E.; Lee, S.; Jung, D.W.; Yamada, Y.; Kleinman, H.K. Laminin-1 and laminin-2 g-domain synthetic peptides bind syndecan-1 and are involved in acinar formation of a human submandibular gland cell line. J. Biol. Chem. 1998, 273, 28633-28641.

25. Hozumi, K.; Suzuki, N.; Nielsen, P.K.; Nomizu, M.; Yamada, Y. Laminin $\alpha 1$ chain LG4 module promotes cell attachment through syndecans and cell spreading through integrin $\alpha 2 \beta 1$. J. Biol. Chem. 2006, 281, 32929-32940.

26. Woods, A.; Couchman, J.R. Syndecans: Synergistic activators of cell adhesion. Trends Cell Biol. 1998, 8, 189-192. 
27. Kikkawa, Y.; Miner, J.H. Review: Lutheran/B-CAM: A laminin receptor on red blood cells and in various tissues. Connect. Tissue Res. 2005, 46, 193-199.

28. Durbeej, M.; Henry, M.D.; Campbell, K.P. Dystroglycan in development and disease. Curr. Opin. Cell Biol. 1998, 10, 594-601.

29. Suzuki, N.; Hozumi, K.; Urushibata, S.; Yoshimura, T.; Kikkawa, Y.; Gumerson, J.D.; Michele, D.E.; Hoffman, M.P.; Yamada, Y.; Nomizu, M. Identification of $\alpha$-dystroglycan binding sequences in the laminin $\alpha 2$ chain LG4-5 module. Matrix Biol. J. Int. Soc. Matrix Biol. 2010, 29, 143-151.

30. Charonis, A.; Sideraki, V.; Kaltezioti, V.; Alberti, A.; Vlahakos, D.; Wu, K.; Tsilibary, E. Basement membrane peptides: Functional considerations and biomedical applications in autoimmunity. Curr. Med. Chem. 2005, 12, 1495-1502.

31. Hozumi, K.; Akizuki, T.; Yamada, Y.; Hara, T.; Urushibata, S.; Katagiri, F.; Kikkawa, Y.; Nomizu, M. Cell adhesive peptide screening of the mouse laminin $\alpha 1$ chain $\mathrm{G}$ domain. Arch. Biochem. Biophys. 2010, 503, 213-222.

32. Nomizu, M.; Kim, W.H.; Yamamura, K.; Utani, A.; Song, S.Y.; Otaka, A.; Roller, P.P.; Kleinman, H.K.; Yamada, Y. Identification of cell binding sites in the laminin $\alpha 1$ chain carboxyl-terminal globular domain by systematic screening of synthetic peptides. J. Biol. Chem. 1995, 270, 20583-20590.

33. Nomizu, M.; Kuratomi, Y.; Malinda, K.M.; Song, S.Y.; Miyoshi, K.; Otaka, A.; Powell, S.K.; Hoffman, M.P.; Kleinman, H.K.; Yamada, Y. Cell binding sequences in mouse laminin $\alpha 1$ chain. J. Biol. Chem. 1998, 273, 32491-32499.

34. Nomizu, M.; Kuratomi, Y.; Ponce, M.L.; Song, S.Y.; Miyoshi, K.; Otaka, A.; Powell, S.K.; Hoffman, M.P.; Kleinman, H.K.; Yamada, Y. Cell adhesive sequences in mouse laminin $\beta 1$ chain. Arch. Biochem. Biophys. 2000, 378, 311-320.

35. Nomizu, M.; Kuratomi, Y.; Song, S.Y.; Ponce, M.L.; Hoffman, M.P.; Powell, S.K.; Miyoshi, K.; Otaka, A.; Kleinman, H.K.; Yamada, Y. Identification of cell binding sequences in mouse laminin $\gamma 1$ chain by systematic peptide screening. J. Biol. Chem. 1997, 272, 32198-32205.

36. Suzuki, N.; Yokoyama, F.; Nomizu, M. Functional sites in the laminin alpha chains. Connect. Tissue Res. 2005, 46, 142-152.

37. Nomizu, M.; Weeks, B.S.; Weston, C.A.; Kim, W.H.; Kleinman, H.K.; Yamada, Y. Structure-activity study of a laminin $\alpha 1$ chain active peptide segment Ile-Lys-Val-Ala-Val (IKVAV). FEBS Lett. 1995, 365, 227-231.

38. Suzuki, N.; Nakatsuka, H.; Mochizuki, M.; Nishi, N.; Kadoya, Y.; Utani, A.; Oishi, S.; Fujii, N.; Kleinman, H.K.; Nomizu, M. Biological activities of homologous loop regions in the laminin $\alpha$ chain G domains. J. Biol. Chem. 2003, 278, 45697-45705.

39. Shigemasa, Y.; Minami, S. Applications of chitin and chitosan for biomaterials. Biotechnol. Genet. Eng. Rev. 1996, 13, 383-420.

40. Croisier, F.; Jérôme, C. Chitosan-based biomaterials for tissue engineering. Eur. Polym. J. 2013, 49, 780-792.

41. Liu, X.; Ma, L.; Mao, Z.; Gao, C. Chitosan-based biomaterials for tissue repair and regeneration. Adv. Polym. Sci. 2011, 244, 81-128.

42. Chen, H.; Liu, Y.; Jiang, Z.; Chen, W.; Yu, Y.; Hu, Q. Cell-scaffold interaction within engineered tissue. Exp. Cell Res. 2014, 323, 346-351. 
43. Jayakumar, R.; Prabaharan, M.; Sudheesh Kumar, P.T.; Nair, S.V.; Tamura, H. Biomaterials based on chitin and chitosan in wound dressing applications. Biotechnol. Adv. 2011, 29, 322-337.

44. Boateng, J.S.; Matthews, K.H.; Stevens, H.N.; Eccleston, G.M. Wound healing dressings and drug delivery systems: A review. J. Pharm. Sci. 2008, 97, 2892-2923.

45. Ueno, H.; Mori, T.; Fujinaga, T. Topical formulations and wound healing applications of chitosan. Adv. Drug Deliv. Rev. 2001, 52, 105-115.

46. Suh, J.K.; Matthew, H.W. Application of chitosan-based polysaccharide biomaterials in cartilage tissue engineering: A review. Biomaterials 2000, 21, 2589-2598.

47. Chen, Y.H.; Chung, Y.C.; Wang, I.J.; Young, T.H. Control of cell attachment on pH-responsive chitosan surface by precise adjustment of medium pH. Biomaterials 2012, 33, 1336-1342.

48. Yang, D.; Lu, X.; Hong, Y.; Xi, T.; Zhang, D. The molecular mechanism of mediation of adsorbed serum proteins to endothelial cells adhesion and growth on biomaterials. Biomaterials 2013, 34, 5747-5758.

49. Shanmugasundaram, N.; Ravichandran, P.; Reddy, P.N.; Ramamurty, N.; Pal, S.; Rao, K.P. Collagen-chitosan polymeric scaffolds for the in vitro culture of human epidermoid carcinoma cells. Biomaterials 2001, 22, 1943-1951.

50. Zhu, N.; Li, M.G.; Guan, Y.J.; Schreyer, D.J.; Chen, X.B. Effects of laminin blended with chitosan on axon guidance on patterned substrates. Biofabrication 2010, 2, doi:10.1088/1758-5082/2/4/ 045002 .

51. Martin-Lopez, E.; Alonso, F.R.; Nieto-Diaz, M.; Nieto-Sampedro, M. Chitosan, gelatin and poly(L-lysine) polyelectrolyte-based scaffolds and films for neural tissue engineering. J. Biomater. Sci. Polym. Ed. 2012, 23, 207-232.

52. Masuko, T.; Iwasaki, N.; Yamane, S.; Funakoshi, T.; Majima, T.; Minami, A.; Ohsuga, N.; Ohta, T.; Nishimura, S. Chitosan-rgdsggc conjugate as a scaffold material for musculoskeletal tissue engineering. Biomaterials 2005, 26, 5339-5347.

53. Mochizuki, M.; Kadoya, Y.; Wakabayashi, Y.; Kato, K.; Okazaki, I.; Yamada, M.; Sato, T.; Sakairi, N.; Nishi, N.; Nomizu, M. Laminin-1 peptide-conjugated chitosan membranes as a novel approach for cell engineering. FASEB J. 2003, 17, 875-877.

54. Hozumi, K.; Otagiri, D.; Yamada, Y.; Sasaki, A.; Fujimori, C.; Wakai, Y.; Uchida, T.; Katagiri, F.; Kikkawa, Y.; Nomizu, M. Cell surface receptor-specific scaffold requirements for adhesion to laminin-derived peptide-chitosan membranes. Biomaterials 2010, 31, 3237-3243.

55. Yamada, Y.; Hozumi, K.; Katagiri, F.; Kikkawa, Y.; Nomizu, M. Laminin-111-derived peptide-hyaluronate hydrogels as a synthetic basement membrane. Biomaterials 2013, 34, 6539-6547.

56. Yamada, Y.; Hozumi, K.; Katagiri, F.; Kikkawa, Y.; Nomizu, M. Biological activity of laminin peptide-conjugated alginate and chitosan matrices. Biopolymers 2010, 94, 711-720.

57. Yamada, Y.; Hozumi, K.; Nomizu, M. Construction and activity of a synthetic basement membrane with active laminin peptides and polysaccharides. Chemistry 2011, 17, 10500-10508.

58. Hansson, A.; Hashom, N.; Falson, F.; Rousselle, P.; Jordan, O.; Borchard, G. In vitro evaluation of an rgd-functionalized chitosan derivative for enhanced cell adhesion. Carbohydr. Polym. 2012, 90, 1494-1500.

59. Matsuda, A.; Kobayashi, H.; Itoh, S.; Kataoka, K.; Tanaka, J. Immobilization of laminin peptide in molecularly aligned chitosan by covalent bonding. Biomaterials 2005, 26, 2273-2279. 
60. Hozumi, K.; Sasaki, A.; Yamada, Y.; Otagiri, D.; Kobayashi, K.; Fujimori, C.; Katagiri, F.; Kikkawa, Y.; Nomizu, M. Reconstitution of laminin-111 biological activity using multiple peptide coupled to chitosan scaffolds. Biomaterials 2012, 33, 4241-4250.

61. Hozumi, K.; Yamagata, N.; Otagiri, D.; Fujimori, C.; Kikkawa, Y.; Kadoya, Y.; Nomizu, M. Mixed peptide-chitosan membranes to mimic the biological activities of a multifunctional laminin a1 chain LG4 module. Biomaterials 2009, 30, 1596-1603.

62. Ikemoto, S.; Mochizuki, M.; Yamada, M.; Takeda, A.; Uchinuma, E.; Yamashina, S.; Nomizu, M.; Kadoya, Y. Laminin peptide-conjugated chitosan membrane: Application for keratinocyte delivery in wounded skin. J. Biomed. Mater. Res. A 2006, 79, 716-722.

63. Mochizuki, M.; Yamagata, N.; Philp, D.; Hozumi, K.; Watanabe, T.; Kikkawa, Y.; Kadoya, Y.; Kleinman, H.K.; Nomizu, M. Integrin-dependent cell behavior on ECM peptide-conjugated chitosan membranes. Biopolymers 2007, 88, 122-130.

64. Otagiri, D.; Yamada, Y.; Hozumi, K.; Katagiri, F.; Kikkawa, Y.; Nomizu, M. Cell attachment and spreading activity of mixed laminin peptide-chitosan membranes. Biopolymers 2013, 100, 751-759.

65. Kasai, S.; Urushibata, S.; Hozumi, K.; Yokoyama, F.; Ichikawa, N.; Kadoya, Y.; Nishi, N.; Watanabe, N.; Yamada, Y.; Nomizu, M. Identification of multiple amyloidogenic sequences in laminin-1. Biochemistry 2007, 46, 3966-3974.

66. Urushibata, S.; Hozumi, K.; Ishikawa, M.; Katagiri, F.; Kikkawa, Y.; Nomizu, M. Identification of biologically active sequences in the laminin $\alpha 2$ chain $\mathrm{G}$ domain. Arch. Biochem. Biophys. 2010, 497, 43-54.

67. Hibino, S.; Shibuya, M.; Hoffman, M.P.; Engbring, J.A.; Hossain, R.; Mochizuki, M.; Kudoh, S.; Nomizu, M.; Kleinman, H.K. Laminin $\alpha 5$ chain metastasis- and angiogenesis-inhibiting peptide blocks fibroblast growth factor 2 activity by binding to the heparan sulfate chains of CD44. Cancer Res. 2005, 65, 10494-10501.

68. Mochizuki, M.; Philp, D.; Hozumi, K.; Suzuki, N.; Yamada, Y.; Kleinman, H.K.; Nomizu, M. Angiogenic activity of syndecan-binding laminin peptide AG73 (RKRLQVQLSIRT). Arch. Biochem. Biophys. 2007, 459, 249-255.

69. Hibino, S.; Shibuya, M.; Engbring, J.A.; Mochizuki, M.; Nomizu, M.; Kleinman, H.K. Identification of an active site on the laminin $\alpha 5$ chain globular domain that binds to CD44 and inhibits malignancy. Cancer Res. 2004, 64, 4810-4816.

70. Streuli, C.H.; Akhtar, N. Signal co-operation between integrins and other receptor systems. Biochem. J. 2009, 418, 491-506.

71. Masuda, R.; Mochizuki, M.; Hozumi, K.; Takeda, A.; Uchinuma, E.; Yamashina, S.; Nomizu, M.; Kadoya, Y. A novel cell-adhesive scaffold material for delivering keratinocytes reduces granulation tissue in dermal wounds. Wound Repair Regen. 2009, 17, 127-135.

(C) 2015 by the authors; licensee MDPI, Basel, Switzerland. This article is an open access article distributed under the terms and conditions of the Creative Commons Attribution license (http://creativecommons.org/licenses/by/4.0/). 